\title{
AJARAN PENDIDIKAN ANTI KORUPSI IBNU ATHAILLAH (Menggali Nilai Pendidikan Moral-Spritual dari Sebagian Untaian Hikmah Kitab Al-Hikam)
}

\author{
Zaitur Rahem \\ Institut Ilmu Keislaman Annuqayah Guluk-Guluk Sumenep Madura \\ Email:zaitur_rahem@yahoo.co.id/kaduara@gmail.com
}

\begin{abstract}
Absract
Corruption here has been ingrained. From year to year, the number of corruption continue to grow. Spread out to various corners of the bureaucracy and social status. Some movement of the Government and tactical systemic organs do. Eradication and the fight against corruption as no betaji. Therefore, one captured, grew so many actors who perform the same action. Back to the sociological typology of Indonesian society, corruption is contrary to the cultural roots of our ancestors. Corruption odds for causing corruption in various aspects of life in Indonesia. There are so many people get hurt and become victims of corrupt practices. Perhaps, therapy metaphysical version of Ibn 'Athaillah through counsels Al-Hikam bidder will be octopus of corruption in Indonesia. At least, this wisdom can be banged strands of consciousness and the hearts of all elements of the Indonesian nation.
\end{abstract}

Key Word: Theology, Sufism, Corruption

\begin{abstract}
Abstrak
Korupsi di Indonesis sudah mendarah daging. Dari tahun ke tahun, angka korupsi terus bertambah. Menyebar ke berbagai sudut birokrasi dan status sosial. Sejumlah gerakan dari Pemerintah dan organ taktis sistemik dilakukan. Pemberantasan dan perlawanan terhadap praktik korupsi seperti tak betaji. Sebab, satu ditangkap, tumbuh sekian oknum yang melakukan tindakan yang sama. Kembali kepada tipologi sosiologis masyarakat Indonesia, praktik korupsi ini bertentangan dengan akar budaya nenek moyang. Korupsi bertentangan karena membuat kerusakan di berbagai sendi kehidupan bangsa Indonesia. Ada sekian orang yang tersakiti dan menjadi korban dari praktikpraktik korupsi. Mungkin, terapi metafisik versi Ibnu 'Athaillah lewat nasehat-nasehat Al-Hikam akan menjadi penawar gurita korupsi di Indonesia. Setidaknya, untaian hikmah ini bisa menggedor kesadaran dan hati semua elemen bangsa Indonesia.
\end{abstract}

Kata Kunci: Teologi, Sufistik, Korupsi 
Zaitu Rahem, Ajaran Pendidikan Anti Korupsi Ibnu Athaillah (Menggali Nilai Pendidikan Moral-Spritual dari Sebagian Untaian Hikmah Kitab Al-Hikam)

\section{Pendahuluan}

Penyakit sosial (social-patology), berupa praktik korupsi di kawasan negeri ini semakin kronis. Efeknya, tatanan budaya masyarakat tidak menentu. Praktik pidana korupsi, realitasnya terjadi di semua sektor pemerintahan. Mulai dari birokrasi papan atas hingga akar rumput (grass root). Pelaku korupsi diketahui belakangan dilakukan oleh sejumlah elemen, dengan kapasitas, identitas sosial, dan latar akademik yang beragam. Fakta ini terkuak, setelah sayap taktis pemerintah, yang memeliki kewenangan melakukan penangkapan terhadap sejumlah oknum yang diduga melakukan praktik korupsi. Oknum-oknum bersangkutan terdata berlatar belakang pendidikan tinggi, pengalaman banyak, dan harta melimpah. Praktik korupsi mewabah. Terjadi di semua lini kehidupan. Tak peduli, dinas, institusi, atau lembaga sosial dan keagamaan. Praktik korupsi menjebak semua elemen terjungkal, pelakunyacepat mendapat sorotan publik, dan banyak orang yang merasa prihatin. Korupsi, tak bisa lepas dari akar lingusitiknya corruptus. Corruptus memiliki makna aktifitas merusak. Korupsi sebagai sebuah perilaku merusak, sangat menggangu ketenangan masyarakat. Corruptus sendiri dalam praktiknya bisa terjadi dimana saja, dalam kontes sosial. Akan tetapi, korupsi yang sering terjadi selama ini, adalah kegiatan merusak kepercayaan publik, karena menilep dan mencuri materi yang peruntukannya untuk umum (rakyat).

Korupsi di Indonesia dalam 'sejarahnya' sudah menyeret banyak tokoh penting. Bahkan, sejumlah oknum yang diberi mandat sebagai penentu hukum (hakim) terseret ke praktik korupsi. Sebagai contoh, Bupati Pamekasan (A. Syafi'e) dan Bangkalan (Fuad Amien Imron) Madura Jawa Timur terjaring Operasi Tangkap Tangan (OTT) oleh KPK RI. Meski, dalam kajian hukum, oknum-oknum bersangkutan melakukan praktik korupsi karena faktor pribadi atau sistemik melakukan praktik korupsi. Tak penting membahasa pribadi dan sistemik, karena praktik korupsi selama ini menjadi musuh semua masyarakat di Indonesia. Kajian hukum mengidealkan pemberantasan praktik perusak tatanan sistem dan sosial masyarakat dengan seadil-adilnya. Praktik korupsi juga sudah dipandang sebagai kejahatan luar biasa. Sebab, selain merugikan negara juga mencemarkan nama baik citra sistem di mana oknum bersangkutan bekerja. Pemerintah gencar melakuka gerakan perlawanan terhadap praktik korupsi. Pada tahun 2016 lalu, pemerintah secara tegas melakukan sweeping ke sejumlah dinas dan instansi birokasi yang diduga 'sebagai sarang korupsi'. Hasilnya, petugas berhasil menangkap 
tangan pejabat di sejumlah institusi dan dinas melakukan praktik suap-menyuap, dan menilep anggaran negara. ${ }^{1}$

Praktik korupsi sangat membahayakan masa depan suatu komunitas. Dalam konteks telogi-islam sendiri, praktik korupsi perbuatan syaiah (thabi'ah syaiah) yang memiliki efek mudharat (negatif) bagi lingkungan sekitar. Dampak terhadap jiwa juga sangat fatal. Dalam pandangan ajaran agama Islam, barang siapa yang memakan barang haram dalam jumlah sedikit atau banyak, akan berpengaruh buruk bagi ibadah dan nalarnya. Sehingga, dalam Islam ada konsep amar ma'ruf nahi mungkar dan shalat merupakan benteng terakhir bagi semua umat Islam agar bisa terhindar dari perbuatan mungkar dimaksud. Betapa jahatnya praktik korupsi, sehingga selama ini kasus korupsi selalu menempati posisi paling strategis yang diperhatikan masyarakat di Negara Kesatuan Republik Indonesia (NKRI). Meskipun semua orang menyadari, praktik korupsi di Indonesia sudah menggurita. Dalam rentang waktu yang cepat, pembasmian praktik korupsi sangat sulit. Akan tetapi, harapan harus tetap ada. Karena, melihat gerakan pemerintah, perlawanan terhadap praktik korupsi sudah signifikan. Lambat, laun ikhtiyar (gerakan) tersebut akan berhasil. Tinggal menunggu waktu, dan komitmen semua masyarakat di Indonesia untuk bergerak bersama melawan Pemberantasan korupsi. Dan, Komisi Pemberantasan Korupsi (KPK) Repubik Indonesia menjadi representasi gerakan masyarakat dalam memusnahkan praktik korupsi.

Melihat realitas korupsi di Indonesia yang terus mengakar ini, perlu kajian empiris-akademis. Salah satunya, korupsi bisa dilihat sebagai sebuah perilaku sosial yang menyimpang (khilaf). Sebab, perilaku korupsi tidak pernah ada pada masa awal terbentuknya nusantara ini. Sehingga, korupsi dalam tataran empiris merupakan fenomena baru pasca komunitas negeri ini mengenal sentuhan baru sains dan tekhnologi. Praktik korupsi yang marak akhir-akhir ini bisa dibaca sebagai perilaku yang menodai kesucian harapan leluluhur masyaakat Indonesia. Sebab, nenek moyang negeri ini tidak pernah mewariskan perilaku menyimpang melakukan praktik korupsi.

Praktik korupsi secara yuridis-legailis konstitusional sangat membahayakan. Dalam konteks telogi-islam sendiri, praktik korupsi merupakan perbuatan tercela (immoral) yang memiliki efek mudharat bagi lingkungan sekitar. Dampak dimensional

\footnotetext{
${ }^{1}$ http://nasional.kompas.com/read/2016/12/14/11192801/kaleidoskop.2016.operasi.tangkap.tangan.terban yak.sepanjang.sejarah.kpk?page=all
} 
Zaitu Rahem, Ajaran Pendidikan Anti Korupsi Ibnu Athaillah (Menggali Nilai Pendidikan Moral-Spritual dari Sebagian Untaian Hikmah Kitab Al-Hikam)

korupsi juga sangat fatal. Barang siapa yang memakan barang haram dalam jumlah sedikit atau banyak, akan berpengaruh buruk bagi ibadah dan nalarnya.

Sehingga, dalam Islam ada konsep amar ma'ruf nahi mungkar dan shalat merupakan benteng terakhir bagi semua umat Islam agar bisa terhindar dari perbuatan mungkar dimaksud. Betapa jahatnya praktik korupsi, sehingga selama ini kasus korupsi selalu menempati posisi paling strategis yang diperhatikan masyarakat di Negara Kesatuan Republik Indonesia (NKRI). Meskipun semua orang menyadari, praktik korupsi di Indonesia sudah menggurita. Dalam rentang waktu yang cepat, pembasmian praktik korupsi sangat sulit. Akan tetapi, harapan harus tetap ada. Karena, melihat gerakan pemerintah, perlawanan terhadap praktik korupsi sudah signifikan. Lambat, laun ikhtiyar (gerakan) tersebut akan berhasil. Tinggal menunggu waktu, dan komitmen semua masyarakat di Indonesia untuk bergerak bersama melawan Pemberantasan korupsi. Melihat realitas korupsi di Indonesia, perlu kajian empiris-akademis. Salah satunya, korupsi bisa dilihat sebagai sebuah 'tradisi menyimpang khas nusantara'. Perilaku melakukan praktik korupsi ini tidak pernah ada pada masa awal terbentuknya nusantara. Sehingga, korupsi dalam tataran empiris adalah sebuah fenomena baru pasca komunitas negeri ini mengenal sentuhan baru sains dan tekhnologi. Praktik korupsi yang marak akhir-akhir ini bisa dibaca secara objektif, bahwa sejatinya nenek moyang negeri ini tidak pernah mewariskan perilaku menyimpang melakukan praktik korupsi. Mengapa praktik korupsi terjadi dan menjangkiti sejumlah elemen di Indonesia? Seperti apa gambaran teologi sufistik Ibnu Athaillah sebagai gagasan pendidikan berbasis moral spiritual menangkap ancaman praktik korupsi?

\section{Ibnu 'Athaillah dan Satire-Kritis Beban Spiritual}

Ibnu 'Athaillah memiliki nama lengkap Ibnu 'Athaillah Al-Sakandari. Beliau familir di tengah-tengah masyarakat muslim dunia karena karya fenomenalnya, AlHikam. Beliau lahir pada pertengahan abad ke 7H/13 M. Tanah kelahiran beliau adalah Alexandria (nama kota pada masa pemerintahan Mamluk, pada masa awal). Ibnu 'Athaillah pada masanya dikenal sebagai seorang Pemikir, Sufistik, Fâqih (ahli fikih), dan Muhaddits. Kemampuan beliau memahami sejumlah disiplin keilmuan diakui oleh banyak ulama pada masanya. Akan tetapi, dalam perjalanan intelektualnya, beliau lebih dikenal sebagai sosok sufi. Fakta itu karena sejumlah karya beliau berisi satire-satire spritual, nasihat-nasihat pengguhan nurani, dan narasi tentang hekekat manusia dan 
kehidupan. Kristalisasi karya sufistik beliau adalah kitab Al- $\underline{\text { Hikam }}$ (Sekumpulan

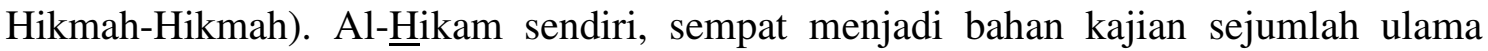
pasca wafat Pengarang. Syarah atas kitab tersebut diantaranya ditulis oleh Ibn 'Abbâd (1332-1390 M) dan Ibn 'Âjibah (1747-1809 M)².

Dalam perjalanan intelektualnya, Ibnu 'Athaillah belajar kepada sejumlah Ulama kharismatik yang dipandang 'alim dan menguasai sejumlah disiplin ilmu agama. Beliau termasuk seorang ilmuwan Muslim yang sangat merdeka dalam memilih guru. Ibnu 'Athaillah tidak pernah memang status dan identitas gurunya. Terbukti, sejumlah guru beliau memiliki aliran berbeda-beda. Seperti dari aliran mazhab Maliki. Imam Sibawaih El-Hasany, menjelaskan, Guru-guru beliau diantaranya Abu al-“Abbas alMursi (w. 1288 M). Guru beliau ini termasuk salah seorang ahli fikih dan Sufi kenamaan dalam aliran thariqat Syâdiliyyah. Thariqat Syâdiliyyah sendiri pada masa Ibnu 'Athaillah tumbuh menyebar di semenanjung Maroko dan Afrika Utara. Dalam perjalanan kethariqatannya, Ibnu 'Athaillah sendiri kemudian tercatat sebagai Sykeh Sufi yang menempati urutan ke 21 dalam Thariqat Syadiliyyâh. Penting untuk diamati, bahwa sosok Ibnu 'Athaillah merupakan ilmuwan sufistik kharismatik. Keilmuannya yang multialenta tak mematikan kesadaran ramahnya kepada seorang guru. Beliau, merupakan murid yang sangat hormat dan mengagungkan gurunya. Terbukti, pasca wafatnya al-Mursi, Ibnu 'Athaillah melanjutkan perjuangan Sufistik sang Guru’

Selain Al-Hikam, Ibnu 'Athaillah juga menulis sejumlah kitab fiqih bergengsi. Diantaranya, Al-Tanwir fi Isqaht al-Tadbir, 'Unwan at-Taufiq fi 'Adab al-Thariq, Miftahul Falah, dan Al-Qaul al-Mujarrad fi al-Ism al-Mufrad. Karya beliau yang terakhir ini diketahui sebagai manuskrip tektulias atas tanggapan terhadap pernyataan Ibn Taymiyah tentang persoalan tauhid. Kisah seputar kehebatan ulama Ibnu 'Athaillah bisa dilacak di sejumlah kitab turas di pusat-pusat lembaga pendidikan Islam tanah air. Nama Ibnu 'Athaillah di kenal luas masyarakat Muslim di seluruh penjuru dunia. Di Indonesia, nasehat-nasehat Ibnu 'Athaillah di dalam kitab al-Hikam menjadi bahan renungan paling 'renyah'. Sangat disukai semua kalangan. Karena kekuatan nasehat Ibnu 'Athaillah menggugah secara substansi, dan indah secara sastrawi.

\footnotetext{
${ }^{2}$ Imam Sibawaih El-Hasany, Kitab Hikam. (Jakarta: Zaman, 2015), 23-34

${ }^{3}$ Imam Sibawaih El-Hasany, Al- $\underline{\text { Hikam...., } 9}$
} 
Zaitu Rahem, Ajaran Pendidikan Anti Korupsi Ibnu Athaillah (Menggali Nilai Pendidikan Moral-Spritual dari Sebagian Untaian Hikmah Kitab Al-Hikam)

\section{Teologi Sufistik-Kontekstual ibnu 'Athaillah Melawan Praktik Korupsi}

Fakta tindak pidana korupsi di Indonesia terus saja mengalir. Tidak pernah ada tanda, kisah korupsi akan berakhir. Alur ceritanya juga semakin luas. Semakin liar. Sebab, tindak pidana korupsi mulai menyeruak di semua institusi. Dari level pusat hingga daerah. Jejaring perilaku menilep ini sudah menjadi racun. Efek racunnya menyebar ke berbagai sendi kehidupan sosial. Menjadi mata rantai hirarkis. Sulit dibendung, meski ada peluang disembuhkan. Ibarat kehidupan dunia jamur, jamur penyakit membentuk area khusus dengan miniatur jamur beracun (mikotoksin). Emberio jamur beracun korupsi lahir dari rasa (mind). Wilayah rasa, merupakan variabel paling sensitif dalam miniatur jazad manusia. Seseorang merasa bisa karena rasa memberi informasi berupa inpsirasi, aspirasi, dan motivasi. Informasi yang ditangkap indra visual (body) mengalir menyentuh rasa. Stimulasi materi yang berhasil ditangkap indera visual mendapat respon rasa. Akumulasi indera visual dan rasa menjadi wahdatul wujud (satu kesatuan) yang kemudian meluncur seiring. Tentu, sama-sama menggiring antara indera visual dengan rasa. Apakah rasa memiliki kekuatan lebih dominan dibanding indera visual? Dalam potret ilmiah, diantaranya kajian phisikologi, setiap individu memiliki tiga potensi esensial. Yaitu, badan (body), jiwa (mind), dan zat (matter). Imam alGhazali memiliki pandangan, jiwa memiliki kekuatan lebih dibanding dua potensi yang ada $^{4}$. Jiwa (mind) adalah mekanisme substanstif yang memiliki jaringan subjektif. Kesucian jiwa pada prinsipnya akan menggerakkan body kepada fungsi terbaiknya. Meski demikian, ritme fenomenologis tentang pertumbuhan dan perkembangan individu tidak bisa lepas dari badan (body). Individu bisa berkembang karena kematangan pertumbuhannya. Petumbuhan individu akan mengantarkan pada maqam ibadullah almuhklisîn ketika jiwanya/perkembangannya stabil ${ }^{5}$.

Korupsi sebagai kejahatan luar biasa. Karupsi menjadi penyakit masyarakat yang menjengkelkan (patology social). Penyakit sosial, dalam kaca mata ilmu pengetahuan kontemporer bermula dari gerai rasa seseorang untuk melangkahi eksistensinya. Terlena dan tergoda material (Vedi R. Hadits, 2010). Martabat kemanusiaan yang semula menjadi prioritas hidup seseorang dalam berkehidupan pudar. Faktor penyebabnya banyak. Mulai dari gairah sensitifitas terhadap material

\footnotetext{
${ }^{4}$ Marmura. Al-Ghazali The Incoherence of the Philosophers (2nd edition). Printing Press, Brigham, tt., 45. Bisa juga dibaca di dalam kitab ابيها الولد (ayyuhal walad) dan كيمياء السعا دة (kimiatus sa'adah).

${ }^{5}$ Zaitur Rahem, Memutus Mikotoksin Korupsi, Duta Masyarakat, 2015
} 
berlebihan atau tekanan libido kekuasaan. Apa yang menjadi larangan agama dan kultur-sosial dengan leluasa bisa dipungkiri. Manusia yang bertabiat semacam ini termasuk kelompok yang tak berhati. Pandangan Ibnu Athaillah (w. 1350 M), manusia terdiri dari komponen daya (phisikis) dan rasa (pyishikologis). Kedua komponen ini merupakan ekosistem yang dinamis. Satu sakit, maka akan sakit seluruhnya. Karena satu sama lain saling mendukung, meski fungsinya terkadang berbeda.

Menata, meruwat, dan merawat hati adalah tugas manusia. Hati adalah komponen terhalus yang menggerakkan ekosistem badan lainnya. Hati yang rusak bisa berakibat fatal terhadap anggota badan lainnya. Kitab al-Hikam karya Ibnu 'Athaillah merupakan manuskrip spiritual membersihkan hati. Untaian nasihat penuh nilai di dalam karya ini orientasinya sebagai obat penyakait hati. Fakta hidup dewasa ini, sejumlah orang menganggap materi (harta) adalah segalanya. Kemewahan hidup di dunia menjadi tujuan paling asasi. Sehingga, ada sekian kejadian, saudara saling terkam dengan saudara sendiri memerebutkan harta. Harta benda sudah menutup hasrat kepada realitas yang lebih substansial. Al-Ghazali mengutip pesan Nabi Muhammad Saw menegaskan, hati adalah benteng terakhir manusia. Pasca perang fisik, umat Islam akan menghadapi perang yang jauh lebih besar, yaitu perang melawan hawa nafsu

$$
\text { مر حبا بكم قد متم من الجها د الا صغر الى الجهاد الاكبر ) }
$$

Sedangkan Ibnu 'Athaillah melalui sejumlah narasi sufistiknya di dalam kitab Al-Hikam mengajak umat (Islam) untuk belajar menjadi manusia yang sesungguhnya. Manusia dengan sebaik-baik ciptaan Tuhan (QS. 68:4). Kelalaian seseorang dalam menata hatinya bisa berpengaruh kepada perilaku dan nalar yang dimiliki. Ketajaman hati salah satunya bisa dilakukan seseorang dengan mengisi hati dengam dzikir. Hati yang bersih akan mengarahkan pemiliknya menuju puncak kenikmatan. Dzikir, secara leksikal berarti ingat. Ingat kepada yang menciptakannya. Yaitu Allah Swt. Namun, secara holistik, dzikir memiliki makna aktualisasi ingat kepada Tuhan. Makna yang kedua ini dmenginginkan ada praktik dimensional untuk bisa mencapai keridlaan Tuhan. Orang ingat berarti menggerakkan semua komponen badan untuk menuju kepada objek yang diingat. Hati yang dihiasi dengan ornamen dzikir mengekspresikan sikap teladan. Segala gerak-gerik dalam hidup dimaksudkan untuk kesejahteraan kehidupan banyak orang. Syekh pengarang kitab al-Hikam ini mencoba menarik makna teks pada peran kontekstual. Kesadaran menjadikan hati sebagai pandu dalam berjalan 
Zaitu Rahem, Ajaran Pendidikan Anti Korupsi Ibnu Athaillah (Menggali Nilai Pendidikan Moral-Spritual dari Sebagian Untaian Hikmah Kitab Al-Hikam)

manfaatnya juga untuk menekan ancaman godaan nafsu fisikal. Hati yang kosong akan menjadi buas. Bahkan, hati yang dibiarkan tidak terawat bisa menebar bahaya dan kejahatan (Ibnu 'Athaillah: 51-67). Patologi sosial yang merajalela di tanah air ini kemungkinan karena manusia enggan menjaga hatinya. Kecintaan terhadap dunia membutakan cinta kepada sang Pemilik kemegahan.

Jebakan rasa ingin menikmati kenikmatan dunia akan terus mengiringi perjalanan seseorang. Selama bumi ada, maka pernik-pernik dunia akan bertahan. Perilaku korupsi identik dengan keinginan rasa seseorang untuk bisa memiliki atau menguasai materi. Wujud materi berupa koin (rupiah). Koin secara substansi adalah umpan terhadap keinginan besar seseorang. Setelah mendapatkan koin, maka keinginankeinginan lainnya akan menjadi-jadi. Keinginan mengumpukan sekian koin materi ini, dalam pandangan Ibnu 'Athaillah karena manusia merasa tidak ada yang mengurus kebutuhannya. Padahalam, Allah terus menentukan segala kebutuhan manusia (QS. 65: 3). Ibnu 'Athaillah di dalam untaian hikmahnya menjelaskan,

$$
\text { ارح نفسك من التد بير فما قام به غيرك عنك لا تقم به لنفسك) }
$$

Istirahatkan dirimu dari ikut mengatur urusanmu. Sebab, apa yang telah diurus untukmu oleh selainmu tak perlu lagi kau turut mengurusnya. ${ }^{6}$

Nasehat sang Ulama kenamaan ini menyiratkan kritik metaforis akan perilaku manusia. Keinginan seseorang dalam mengejar kepuasan materi sangat kentara. Sehingga, sisi hakekat dari dimensi penciptaan dirinya ke muka bumi menjadi abai begitu saja. Penyalahgunaan tugas dan kewajiban sebagai mahluk (hamba) terlihat sangat kentara. Semua aktifitas akan dilakukan untuk mencapai pincak keinginannya. Praktik korupsi tidak bisa dilepaskan dari hasrat manusia karena merasa tidak percaya dengan kekuatan Tuhannya.

KH Agoes Ali Masyhuri di dalam buku Belajarlah kepada Lebah dan Lalat menjelaskan kiat-kiat mendapatkan rezeki. Rezeki bisa lapang dengan dua hal, yaitu syukur dan sabar. Sabar dan bersyukur menerima pemberian Tuhan. Bergelimang harta belum tentu bahagia. Namun, miskin harta bisa menyebabkan seseorang ingkar kepada Tuhan. Ada dua sisi problematis yang harus diperhatikan manusia dalam mencari rezeki. Kaya memang menyenangkan. Namun, kaya hati jauh lebih menyenangkan dibanding kaya harta benda. Sebenarnya, menurut K.H. Agoes Ali Masyhuri kaya

\footnotetext{
${ }^{6}$ Imam Sibawaih El-Hasany, Al- $\underline{\text { Hikam..., }} 18$
} 
tergantung konteks yang mempergunakan. Kunci utama, orang kaya harus banyak bersyukur dan bersabar. Sebab, kekayaan sudah menjadi kehendak Allah Swt ${ }^{7}$. Teori Ulama khas NU ini akan mengobati derita di tengah krisis perekonomian. Zaman boleh keras, namun keyakinan atas kasih sayang Tuhan tidak boleh lepas dari kandung badan. Krisis ekonomi bukanlah beban yang harus ditakuti. Akan tetapi, belajar kepada karya Kiai sepuh ini, masalah krisis hanya jalan lain menjadikan bangsa Indonesia sebagai bangsa yang besar. Teringat kisah lebah dan lalat di dalam buku ini, Allah memberikan materi pelajaran kepada manusia agar bisa bekerja keras seperti lebah. Meninggalkan rasa malas seperti tingkah laku lalat. Manusia hanya mahluk lemah. Kekuatan Tuhan di atas segalanya. Sayangnya, kondisi riil ini terkadang tidak penah dikaji oleh sebagian besar manusia. Manusia hanya mencari kepuasan duniawi tanpa mempertimbangkan substansi apa yang mereka cari. Tak heran ada banyak ketimpangan selama mejalani proses kehidupan. Sekali lagi, ketika Tuhan dinomorduakan maka harapan menggapai impian akan berlalu begitu saja.

Allah menjamin rezeki setiap mahluk yang berdiam di muka bumi. Seekor ulat yang berada di tempat kering sekalipun pasti akan mendapat makanan. Kunci utama dari hidup adalah sabar dan bersyukur. Pada sebagian halaman, karya ini menjelaskan tentang hikmah sabar dan jaminan rezeki Allah kepada mahluk. Dikisahkan, pada suatu ketika Nabi Muhammad Saw menjelaskan tentang kedatangan Malaikat Jibril. Malaikat Jibril menceritakan kepada Nabi Muhammad Saw perihal seekor semut, ulat, dan katak. Pada suatu waktu Nabi Sulaiman mengerjakan shalat di pinggir sungai. Nabi Sulaimana yang diberi keistimewaan oleh Allah bisa mengerti bahasa binatang heran dengan seekor semut yang sedang membolak balik daun di atas air. Sambil menggigit daun semut memanggil-manggil katak di kedalaman sungai. Sebentar kemudian si katak muncul dan langsung memindahkan semut di atas punggungnya. Katak membawa semut dengan daun yang digigit ke pinggir sungai. Hal itu berulang hingga tiga kali.

Melihat adegan tersebut Nabi Sulaiman bertanya kepada semut. Semut itu menceritakan kepada Nabi Sulaiman bahwa di seberang sugai berdiam seekor ulat. Ia menggantungkan rezekinya kepada semut. "Sehari dua kali saya diantar dua malaikat memberikan makanan itu". Demikian semut memberikan penjelasan kepada Nabi Sulaiman. Nabi Sulaiman bertanya kepada semut tentang dua malaikat itu. Semut

\footnotetext{
${ }^{7}$ K.H. Agoes Ali Masyhuri, Belajarlah kepada Lebah dan Lalat, (Jakarta: Zaman, 2015). 45-50
} 
Zaitu Rahem, Ajaran Pendidikan Anti Korupsi Ibnu Athaillah (Menggali Nilai Pendidikan Moral-Spritual dari Sebagian Untaian Hikmah Kitab Al-Hikam)

mengatakan, dua malaikat itu adalah katak itu. Malaikat menjelma menjadi seekor katak yang mengantar semut ke seberang sungai tempat ulat berdiam. Kisah bertuah ini menjadi cermin bahwa Tuhan Maha Pemurah kepda semua mahluk ciptaannya. Nalar manusia sangat terbatas dan tidak akan mampu menjangkau kebesaran karunia Tuhan.

Perilaku korupsi merupakan aktifitas rasa seseorang yang berlebihan. Sebagaimana disinggung pada sub poin di atas, rasa memiliki keterkaitan dengan wilayah phisikologi. Hasrat menguasai materi karena desakan dari dalam daya. Lalu, menimbulkan respon rasa. Mata melihat emas dan rupiah ratusan juta, lalu rasa tertarik ingin memiliki mencuat menguasai sistem daya-rasa. Menjadi kristalisasi keinginan besar menjadi seorang kaya raya, banyak uang, dan memiliki kekuasaan yang tak tertandingi. Keinginan besar tanpa diimbangi dengan kemapuan mumpuni. Sehingga, mengakibatkan ada satu komponen yang tidak normal. Pada konteks ini, Ibnu 'Athaillah memberikan gambaran melalui hikmah berikutnya,

$$
\text { (اجتهادك فيما ضمن لك و تقصيرك فيما طلب منك دليل على انطما س البصيرة منك) }
$$

Kesungguhanmu meraih apa yang telah dijamin untukmu dan kelalaianmu mengerjakan apa yang dituntut darimu merupakan bukti padamnya mata hatimu (Ibnu 'Athaillah: 18).

Praktik korupsi, merujuk kepada nasehat Ibnu 'Athaillah hanya bisa dilawan dengan dua pendekatan. Pertama, secara internal. Internalisasi ini mengacu kepada semua sistem daya-rasa dalam diri seseorang. Suasana hati menjadi pengendali daya dan rasa dalam jaringan tubuh manusia. Semakin bersih hati seseorang dalam memaknai tanda-tanda kebesaran Tuhan, maka semakin bersih memilih pilihan yang salah dan benar. Kedua, tindakan preventif bisa dilakukan melalui kebijakan yang proporsional. Artinya, niat melawan tindakan amoral harus diiringi dengan pengawalan hukum formal di kawasan manusia berdiam. Kritik Ibnu 'Athaillah di dalam sejumlah untaian kitab Al-Hikamnya secara kontektualis bisa diterapkan. Akan tetapi, aksi progressif substansi nasehat-nasehat Ibnu 'Athaillah semua kembali kepada kesadaran per individu. Seketat apapun aturan baku yang diterapkan, tanpa adanya kesadaran untuk memilih jalan benar, hukum tersebut akan sia-sia belaka. Demikian sebaliknya. Semua elemen dalam sistem kehidupan harus berjalan dinamis. Sehingga, mampu menggerakan peradaban lebih bermartabat. 
Tuhan menjadikan manusia sebagai Penjaga bumi tentu dengan berbagai alasan. Alasan dalam perspektif kemanusiaan, agar semua manusia mampu menjadi hamba Tuhan yang santun dengan semua mahluk di bumi. Manusia adalah mahluk terbaik ciptaan Tuhan (QS. Al-Qalam: 4). Gambaran moral-sosial di bumi menjadi cerminan pada kehidupan selepas dari bumi (yaumi al-hisab). Kehidupan bumi adalah ruang interaksi, aktualisasi, dan dinamisasi tugas dan kewajiban manusia sebagai Penjaga bumi. Selain mengurai tentang hikmah kebersihan hati, Ibnu 'Athaillah di dalam manuskrip spiritual Al- Hikam mengajarkan tentang aturan hidup manusia di bumi. Hidup di bumi bukan semata melampiaskan kenikmatan dalam pandangan bumi. Aturan bumi tidak bisa lepas dengan ajaran sakral langit. Di atas bumi masih ada langit. Demikian seterusnya. Dalam tahap matematis-filosofis, di atas kekuatan manusia (sebagai Penjaga bumi) masih ada kekuatan adikuasa yang menguasai bumi dan isinya. Yaitu, Allah Swt.

Konsep Al- Hikam mengenai keinginan seseorang terhadap dunia adalah meminta sesuatu hanya kepada sang Khalik.

$$
\text { الاتمدن يدك الى الا خد من الخلائق الا ان ترى ان المعطي فيهم مو لا كك فا داكنت كدا لك فخد ما وا فقه العلم }
$$

jangan engkau mengulurkan tangan untuk menerima sesuatu dari makhluk kecuali jika engkau melihat bahwa yang memberi adalah Allah. Jika engkau telah demikian, ambillah apa yang sesuai dengan pengetahuanmu (Ibnu 'Athaillah: 204).

Gejolak kompetisi hidup yang ambisius ini membuat status manusia sebagai Penjaga bumi tergerus. Dari Penjaga bumi akhirnya berubah menjadi Penjahat/Penjilat di bumi. Realitas ini akan mematikan kenikmatan yang Tuhan tumpahkan untuk manusia di muka bumi. Kenyamanan hidup, kedamaian, kebahagiaan selama menjalani kehidupan di bumi tidak mungkin bisa didapatkan. Karena manusia dininabobokkan dengan gejolak nafsu serakah dan ambisi yang tak berbatas. Kekuatan nafsu akan mengaburkan pandangan manusia. Jebakan iri dan dengki akan mudah merasuk dalam jiwa seseorang. Sehingga bisa dilihat di sejumlah tempat, seseorang memilih menghabiskan waktu dengan dunia kerja. Tidak ada ruang mengingat Tuhan, hidup hanya kepentingan uang. Padahal ajaran agama Islam sudah menggariskan, barang siapa yang bekerja tidak berdasarkan perintah Tuhan, maka tidak akan pernah menemukan kepastian. Ajaran Tuhan yang sebagian besar termaktub dalam teks ayat suci al-Quran memiliki maksud untuk kepentingan manusia yang saat ini hidup di bumi. Ajaran al- 
Zaitu Rahem, Ajaran Pendidikan Anti Korupsi Ibnu Athaillah (Menggali Nilai Pendidikan Moral-Spritual dari Sebagian Untaian Hikmah Kitab Al-Hikam)

Quran akan terasa manfaatnya jika mampu dipraktikkan dengan benar oleh manusia. Kekuatan al-Quran bukan hanya untuk maksud dibaca. Lantunan suara bagus itu baik. Akan tetapi menjadi lebih baik ketika diimbangi dengan praktik nyata berdasarkan kehidupan masyarakat bumi. Ayat tentang persaudaraan itu berlaku secara mutlak dalam wilayah kemanusiaan. Sesungguhnya, antara manusia yang satu dengan lainnya (tanpa memandang suku dan keyakinan) memiliki martabat yang sama. Sama-sama memiliki hak untuk hidup berdampingan, saling membantu dalam kesulitan, dan menjaga kedamaian di muka bumi. Prinsip hidup di bumi adalah mematuhi ajaran langit. Caranya, manusia harus memulai dari dirinya sendiri. Jiwa dan raga setidaknya bisa selaras dalam menjalankan kehidupan bumi. Segala tindakan yang menyakiti perasaan manusia lainnya akan menyakiti Tuhan (Qs. As-Syamsi: 9-10). Termasuk, menekan semaksimal mungkin agar tidak ada praktik korupsi di sekitar kehidupan ini. 


\section{Penutup}

Praktik korupsi yang menggurita di Indonesia saat ini pada prinsipnya sebuah gejala normatif dalam kehidupan manusia. Sejumlah oknum yang melakukan tindakan korupsi disebabkan oleh ambisi nafsu dalam diri Pelaku. Ambisi muncul karena faktor ketertarikan daya untuk sama dengan yang lain. Sehingga, pada titik kulminasi timbul hasrat dominan agar semua harapan yang timbul bisa teraktualiasi secara cepat. Tanpa memandang batasan nilai yang berlaku.

Ibnu 'Athaillah dalam Al- $\underline{H i k a m}$ memberikan tawaran konsep solutif menetralisir praktik korupsi. Yaitu, membersihkan hati (القلب) dan menata komitmen hidup( تصوف). Komitmen hidup bisa ditempuh dengan cara sederhana (توسط), sabar (الصبر), bersyukur (السكر), dan menghindari kemegahan material (راهد في الدنبا). Setiap manusia memiliki keinginan yang sama. Akan tetapi, kesadaran untuk menjaga martabat dirinya yang akan membedakan kualitas manusia yang satu dengan lainnya. Kontekstualisasi ajaran Ibnu 'Athaillah menjadi serangkaian strategi spiritual menyelesaian persoalan praktik korupsi di Indonesia. Wallahu a'lam. 
Zaitu Rahem, Ajaran Pendidikan Anti Korupsi Ibnu Athaillah (Menggali Nilai Pendidikan Moral-Spritual dari Sebagian Untaian Hikmah Kitab Al-Hikam)

\section{DAFTAR PUSTAKA}

Aziz, Iwan Jaya, 1994. Ilmu Ekonomi Regional dan Beberapa Aplikasinya di Indonesia, Jakarta: Lembaga Penerbit FE UI.

Al-Hasyimi, Abd. Al-Hamid Muhammad. 1402 H. Lamahat Nafsiyah fi Al-Quran AlKarim, Makkah: Da'wat Al-Haq.

Danner, Victor. 2003. Sufisme Ibnu 'Athaillah, Kajian Kitab al-Hikam (Surabaya: Risalah Gusti,

Dato' Hj. Tuan Ibrahim bin Tuan Man. Syarah al-Hikam (Bandar Pusat. Pahang: t.p., t.t.)

Elhasany, Imam Sibawaih, 2105. Kitab Al-Hikam, Jakarta: Zaman.

Fukuyama, Francis, 2005. Memperkuat Negara:Tata Pemerintahan dan Tata Dunia Abad 21, Jakarta: PT. Gramedia.

Hamzah, Fahri, 2011. Negara, Pasar, dan Rakyat, Jakarta: Yayasan Faham Indonesia. Hasbullah, Jousairi, 2006. Social Capital, Jakarta: MR-United Press

Hatta, Moh, Ekonomi Indonesia di Masa Mendatang, dalam Sri Edi

Swasono (editor), 1985. Sistem Ekonomi dan Demokrasi Indonesia, Jakarta: UI Press

Stern, Frederick Martin. 1980. Capitalisme in America, USA: Richard and CO.

Sindhunata, 1982. Dilema Usaha Manusia Rasional, Jakarta: PT. Gramedia

Hikam, Muhammad AS, 1999, Demokrasi dan Civil Society, Jakarta: LP3ES

Ibn Khaldun, 2004. al-Muqaddimah, Beirut: Dar al-Fikr

Joon Chang, Ha, Ilene Grabel, 2008. Membongkar Mitos Neolib: Upaya Merebut Kembali Makna Pembangunan, Jogjakarta: Insist Press

Masyhuri, KH. Agoes Ali, 2015, Belajarlah kepada Lebah dan lalat, Jakarta: Zaman

Machali, Imam (ed.), 2004. Pendidikan Islam dan Tantangan Globalisasi. Yogyakarta: Ar-Ruzz Media

Mazhahiri, Husain, 1999. Pintar Mendidik Anak, Jakarta: Lentera Basritama

Said Abdullah, MH, 2008, Pendidikan Multikultural, Jakarta: SaiPress

Referensi Kamus dan Al-Qur'an: Al-Quran Terjemah Al-Jumânatul Âli, Revisi terjemah oleh Lajnah pentashih Mushaf al-Qur'an Departemen Agama Republik Indonesia, 2004.

Kamus Besar bahasa Indonesia (KBBI), Kemendikbud RI. Kamus Al-Munawwir. Wikipedia 